\title{
High frequency of persistent hyperplastic primary vitreous and cataracts in p53-deficient mice
}

\author{
Martin B Reichel ${ }^{1}$, Robin R. Ali ${ }^{1,4}$, Fabiana D'Esposito', \\ Alan R. Clarke ${ }^{2}$, Philip J. Luthert ${ }^{3}$, Shomi S. Bhattacharya ${ }^{1}$ \\ and David M. Hunt ${ }^{1}$ \\ ${ }^{1}$ Department of Molecular Genetics, Institute of Ophthalmology, University \\ College London, Bath Street, London EC1V 9EL, UK \\ 2 Department of Pathology, University of Edinburgh Medical School, Teviot \\ Place, Edinburgh, EH8 9AG, UK \\ ${ }^{3}$ Department of Pathology, Institute of Ophthalmology, University College \\ London, Bath Street, London EC1V 9EL, UK \\ 4 corresponding author: tel: 0044171608 6817; fax: 0044171608 6863; \\ email: r.ali@ucl.ac.uk
}

Received 28.4.97; revised 5.8.97; accepted 9.9.97

Edited by R.A. Knight

\begin{abstract}
In order to investigate whether the $p 53$ gene product plays a role in normal eye development, age matched p53-deficient mice and wild-type controls were sacrificed from day 2 to day 21 after birth. Eyes were paraffin-embedded and sectioned. Serial sections were taken at the level of the tunica vasculosa lentis and the hyaloid artery. The terminal dUTP nick-end labelling technique (TUNEL) was used to detect the number of cells displaying DNA fragmentation within these structures. Eyes were also prepared for scanning electron microscopy and resin embedded for semi-thin sections. Adult wild-type mice and p53-deficient mice were examined ophthalmoscopically in vivo. Ophthalmoscopical examination of mice completely deficient in $\mathrm{p} 53$ revealed them to be normal except for the persistence of the hyaloid vasculature, a structure that normally regresses during eye development. In adult animals there was also a high frequency of cataracts. Using morphological assessment and TUNEL we could show that in normal mice, regression of the primary vitreous, which includes the hyaloid artery, the vasa hyaloidea propria as well as the tunica vasculosa lentis, occurs via apoptotic cell death within 5-6 weeks after birth. The number of TUNEL-positive cells within these structures was significantly reduced in the p53-deficient mice in which parts of the hyaloid vasculature persisted and developed into a fibro-vascular retrolental plaque analogous to persistent hyperplastic primary vitreous (PHPV) described in humans. As in humans, PHPV in mice resulted in the development of cataracts. We have identified a role for p53-dependent apoptosis in the regression of the hyaloid vasculature and tunica vasculosa lentis. Our results provide further evidence for the importance of $\mathrm{p} 53$ in normal development and provide the first detailed evidence of its role in postnatal development in remodelling the developing eye.
\end{abstract}

Keywords: eye; development; apoptosis; p53; PHPV
Abbreviations: $\mathrm{Rb}$, retinoblastoma; HVS, hyaloid vascular system; PHPV, persistent hyperplastic primary vitreous; PHTVL, persistent hyperplastic tunica vasculosa lentis; TUNEL, terminal dUTP nick-end labelling; SEM, scanning electron microscopy; H\&E, hematoxylin and eosin

\section{Introduction}

Apoptosis is an important genetically-controlled mechanism for eliminating cells which are either damaged, infected with virus or no longer required, as in the case in tissue turnover, embryogenesis and organ atrophy. It is characterised by a number of features that include cytoplasmic shrinkage, chromatin condensation and internucleosomal DNA fragmentation. Although the role of the p53 gene in apoptosis was originally associated with its protective function in tissue following DNA damage, more recent studies on p53-deficient mice have revealed a high frequency of developmental abnormalities suggesting a function for p53-dependent apoptosis in normal development (Sah et al, 1995; Armstrong et al, 1995). To date very little has been reported on the role of p53 in the developing eye. Since apoptosis is required for development of the mammalian eye (see Papermaster, 1997, for recent review), and since p53 is now known to be required for some apoptotic developmental processes, we decided to ascertain the extent to which this gene is involved in normal eye development. In order to do this we have systematically examined mice with a target disruption of the $p 53$ gene.

The p53 tumour suppressor protein is essential for a variety of different responses, including both cell cycle arrest and the activation of the apoptotic pathway following genotoxic damage (Clarke et al, 1993; Norimura et al, 1996; White, 1996). It can promote apoptosis in a variety of cell types, including those with oncogenic lesions as has been shown in the lens of mice deficient for the retinoblastoma $(\mathrm{Rb})$ tumour-suppressor gene (Morgenbesser et al, 1994). Mice with a targeted disruption of the p53 gene have been generated by several investigators (Donehower et al, 1992; Clarke et al, 1993). All lack any functional p53 protein and show a common phenotype: the mice are prone to developing a variety of tumours that are predominantly of lymphoid lineages (Jacks et al, 1994; Purdie et al, 1994).

During embryogenesis the elimination of obsolete tissue via apoptosis is part of the morphogenetic process leading to the form and/or function of the mature organ. For example, the regression and remodelling of tissue occurs during development of the embryonic tail, interdigital tissue, kidney precursor organs and within the central nervous system. There is increasing evidence that p53 has a role in this process. It has recently been reported that p53deficient mouse embryos have a high frequency of developmental abnormality. This is particularly so in 
females, $25 \%$ of which have defects in neural tube closure, leading to exencephaly and craniofacial malformations which prevent them coming to term (Sah et al, 1995; Armstrong et al, 1995). Vitreal development is another process involving tissue remodelling (Virchow, 1853; Jokl, 1927; Mann, 1964; Balazs et al, 1980). The formation of the vitreous is described as occurring in two phases and results in the primary and secondary vitreous. The hyaloid artery, vasa hyaloidea propria and the posterior part of the tunica vasculosa lentis form the vessels of the primary vitreous known as the hyaloid vascular system (HVS). The presumed function of this transitory network of vessels is to satisfy the metabolic needs of the inner eye during embyrogenesis. This role is gradually taken over by the developing retinal vasculature. Subsequently, the HVS regresses and the vitreous cavity is filled with collagen fibrils, extracellular hyaluronic acid and hyalocytes, forming the secondary vitreous. Occasionally in humans, instead of regressing between the third and the ninth month of gestation, the structures of the primary vitreous persist to give a disorder known as persistent hyperplastic primary vitreous (PHPV). This congenital ocular disorder has been thoroughly reviewed by Reese in his 1955 Jackson memorial lecture (Reese, 1955). It usually occurs unilaterally with no apparent hereditary influence. The hyaloid artery remains, either patent or atresic, and, rising from the disc through the vitreous cavity, is connected with a fibrous tissue membrane covering the posterior surface of the lens. This often leads to proliferation of fibrovascular tissue on the posterior surface of the lens, a condition known as persistent hyperplastic tunica vasculosa lentis (PHTVL). The resultant plaque usually leads to a cataract.

\section{Results}

Ophthalmoscopy of the dilated mouse eye and histological examination revealed bilateral persistence of the hyaloid artery and hyperplasia of the tunica vasculosa lentis

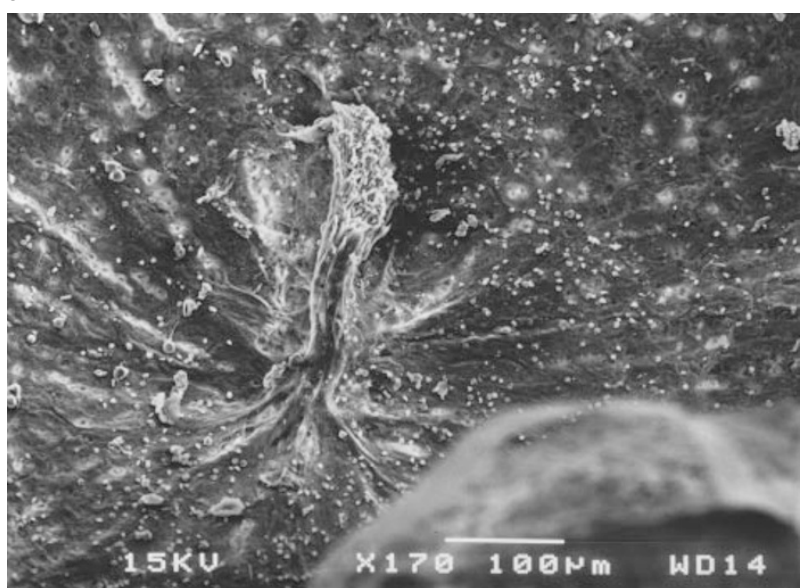

b

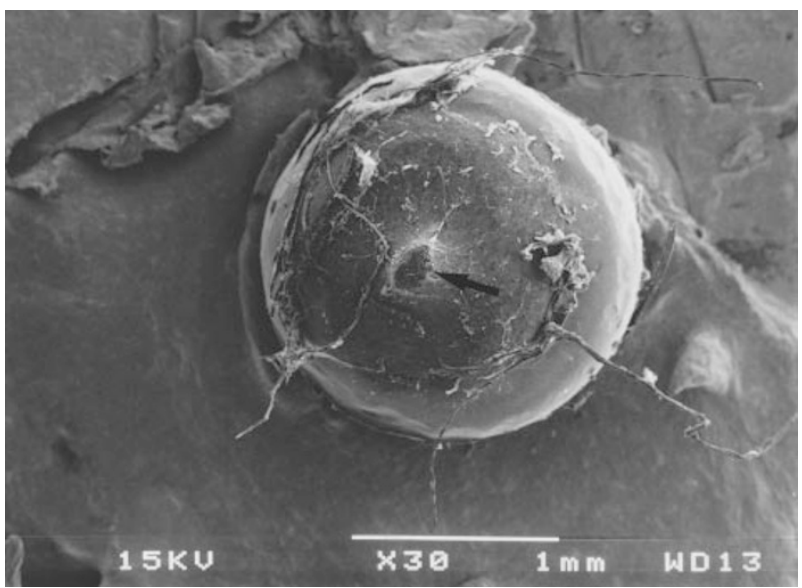

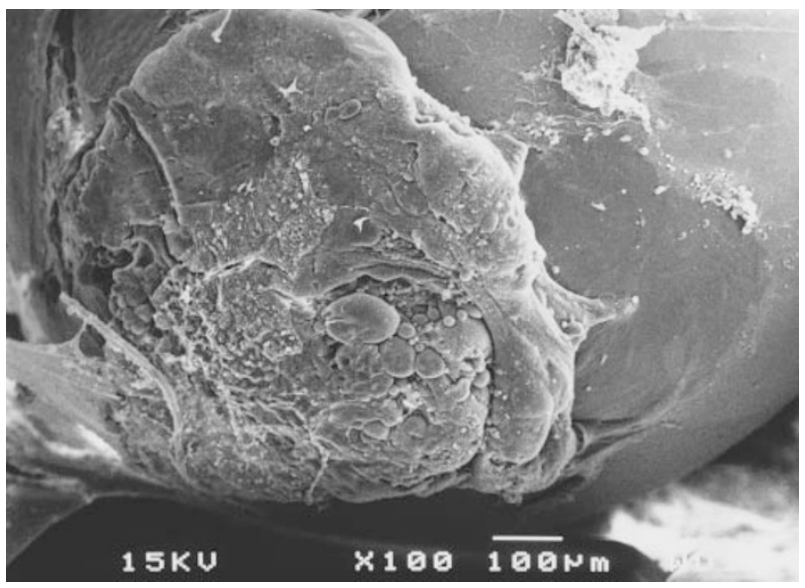

d

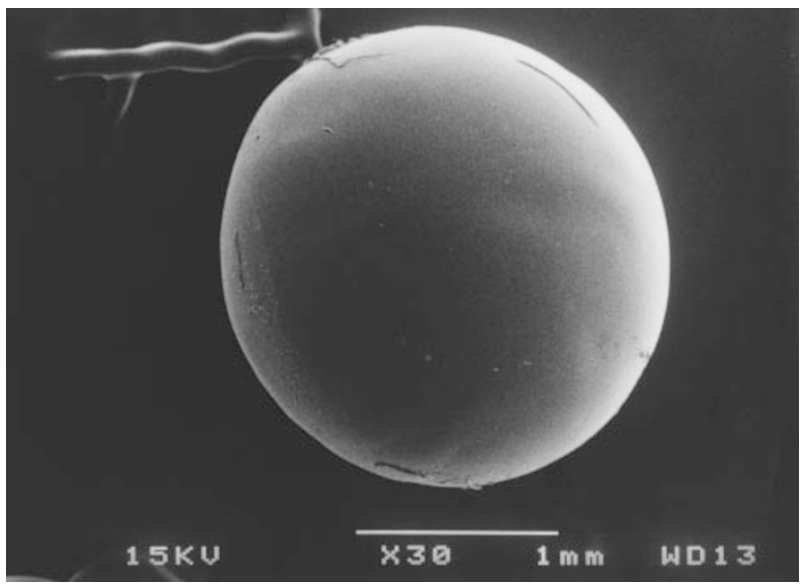

Figure 1 a-c Scanning electron micrograph of an eye from a 2 month old p53 ${ }^{-1}$ - mouse showing: (a) the posterior pole of the retina - the persisting hyaloid artery can be seen in its centre $(170 \times)$; (b) an elevated circular retrolental plaque on the smooth lens surface - in its centre is the broken off stalk of the hyaloid artery (arrow) $(30 \times)$ and (c) bulky mass of retrolental tissue adhering to the posterior lens capsule $(100 \times)$. (d) Scanning electron micrograph of the posterior surface of a lens from a 2 month old BALB/c mouse control revealing a totally smooth capsule $(30 \times)$ 
resulting in a retrolental sheath of fibrovascular tissue in all adult $\mathrm{p} 53^{-1-}$ mice but not in any $\mathrm{p} 53^{-/+}$mice in our colony. Ophthalmoscopic examination of the persistent hyaloid structures became more difficult in older animals due to cataracts. The incidence of cataract information increased with age. While in animals under 4 weeks of age, only $10 \%$ showed lens opacities, $50 \%$ of adults at the age of 2 months and older had dense cataracts, predominantly at the posterior cortex and capsule. No other abnormalities were found. The manifestation of PHPV in ${\mathrm{p} 53^{-1-}}^{-}$animals were found to be variable. Some animals had only a thin, tapering stalk of persisting hyaloid artery which just reached the lens where it spread into a small star-like retrolental plaque without further visible lens changes. However, more than half of the adult animals showed a prominent persisting hyaloid artery (Figure 1a) and a thick retrolental plaque covering half of the posterior lens pole (Figure $1 \mathrm{~b}$ and $\mathrm{c}$ ). There was no sign of hyaloid vasculature remnants or retrolental tissue in any of the adult control animals examined (Figure 1d). Substantial proliferation of the retrolental membrane was observed as early as day 14 after birth (data not shown). Folding of the retina adjacent to the hyaloid artery was observed in adult animals and is most likely due to traction transmitted through the persisting artery to the retina during eye growth. In young animals (2-3 weeks old) the growth of fibrous tissue on the posterior lens capsule led to disruption of the lens capsule. The resulting hydration of the lens and bulging of material into the fibrovascular plaque was observed in many adult cases (Figure 2a and b). In normal adult mice the lens capsule is intact and the primary vitreous is replaced by an acellular secondary vitreous (Figure 2c). The developing cataract could easily be diagnosed ophthalmoscopically. The more prominent form of PHPV in these eyes could only be visualised on histological sections, since the cataract occluded the ophthalmoscopic view of the retrolental tissue.

In BALB/c mice we were able to observe regression of the primary vitreous starting at day 5 when there is a thinning and rarefication of the vessels of the hyaloid vasculature. The number of vascular lumens observed in cross sections taken through the tunica vasculosa lentis diminishes over time and the vasa hyaloidea propria as well as the branches of the hyaloid artery become less abundant. Hyalocytes, the tissue macrophage population of the vitreous, were observed in the vitreous predominantly between days 7 to 14 but are not regularly distributed and were much more numerous in some eyes than in others (Figure $3 a$ and $b$ ). Far fewer macrophages were present in

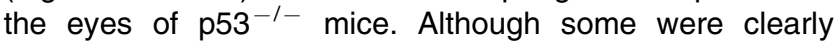
present, we did not see the abundance observed after day 7 in wild-type control animals (Figure 3c). By 6 weeks in control animals there was no evidence of hyaloid vasculature and the primary vitreous had been replaced (Figure 2c). At no point did we observe formation of a fibrovascular retrolental sheath in these mice. Ophthalmoscopic screening of $129 \mathrm{SvH}$ sd mice, from which the $\mathrm{p} 53^{-1-}$ mice were originally derived, did not reveal any abnormality in the regression of the hyaloid vasculature thus excluding the possibility that the abnormal phenotype in the $\mathrm{p} 53^{-1-}$ mice was caused by a mutation present in the 129 mouse strain in a gene linked to the disrupted p53 gene.

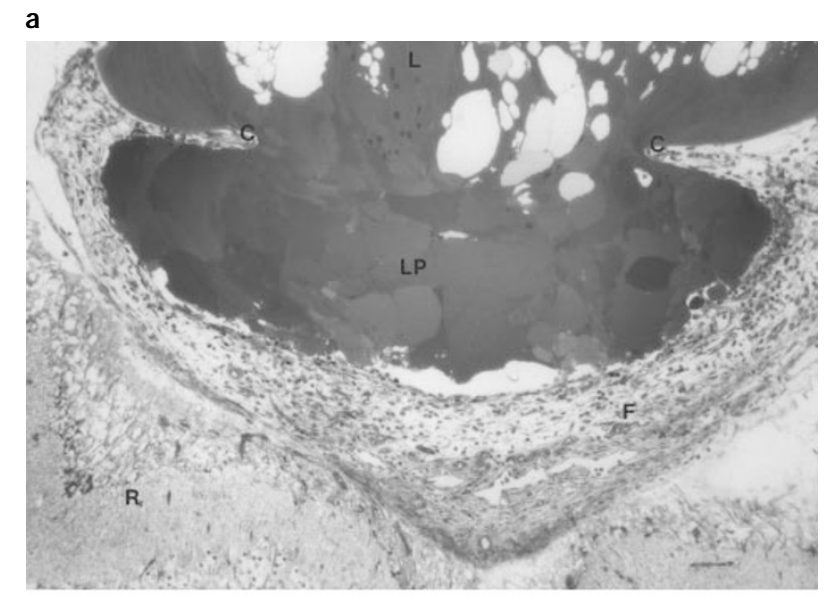

b
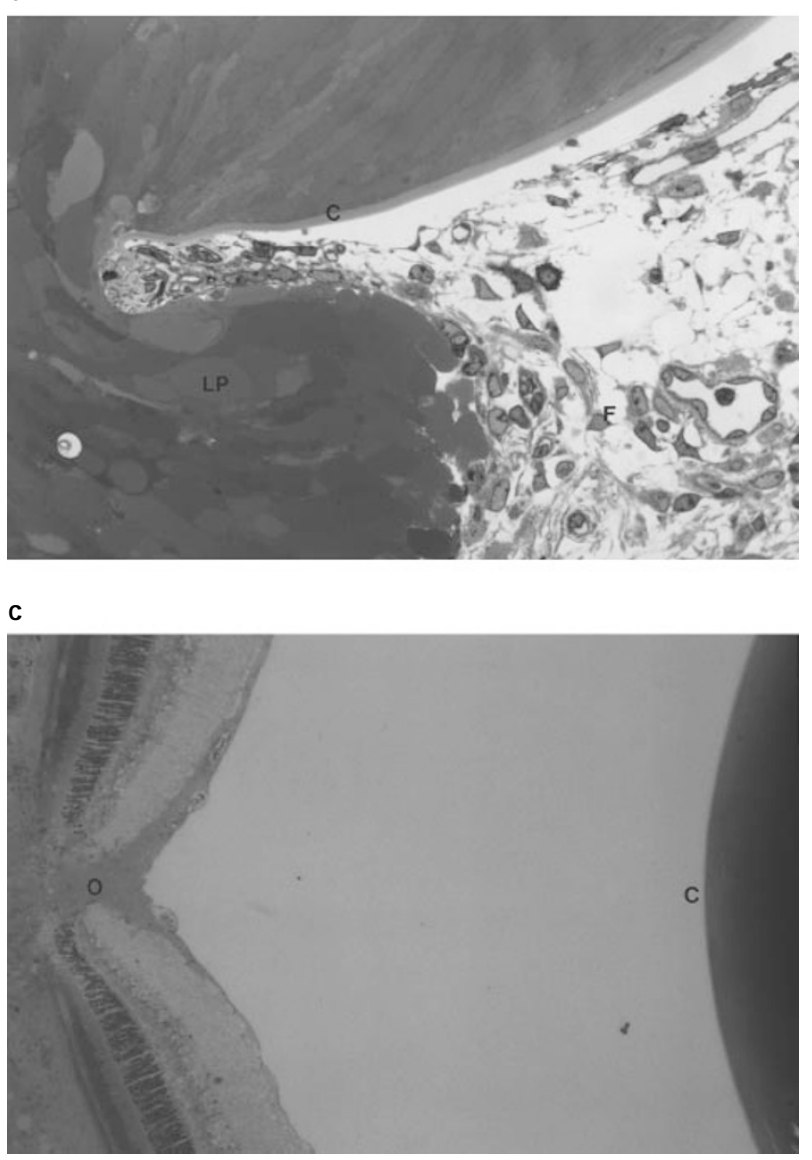

Figure 2 (a, b) Semi-thin sections through a 3 month old p53 ${ }^{-1-}$ mouse eye at the level of the optic nerve, toluidine blue stained, showing: (a) a fibrovascular membrane $(F)$ lying between the retina $(R)$ and the posterior pole of the lens $(L)$ the lens capsule $(C)$ is disrupted and lens material is protruding (LP) $(25 \times)$ (b) an enlarged area of the capsule opening - lens material is bulging out (LP) where the capsule $(\mathrm{C})$ is disrupted, meeting the fibro-vascular tissue $(F)$ at the hyperplastic tunica vasculosa lentis. $(50 \times)$. (c) Semi-thin section through a 2 month old BALB/c mouse eye at the level of the optic nerv (O), toluidine blue stained, showing a smooth lens capsule (C) and acellular secondary vitreous $(10 \times)$ 
Regression of the vascular structures of the primary vitreous in wild-type BALB/c mice appeared to occur by apoptosis: using the terminal dUTP nick-end labelling (TUNEL) technique to stain double stranded DNA breaks, we could observe apoptotic cells within the tunica vasculosa lentis (Figure 4a) and within the regressing hyaloid artery (Figure 4b). On a single section through the

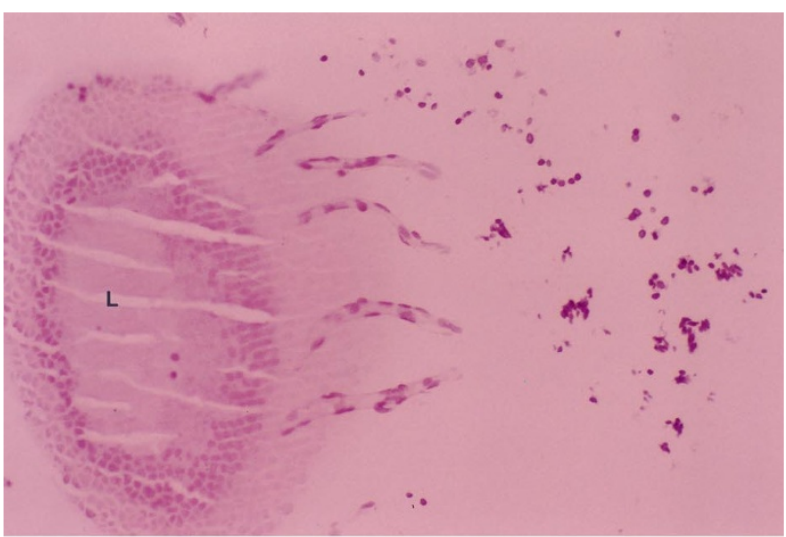

b

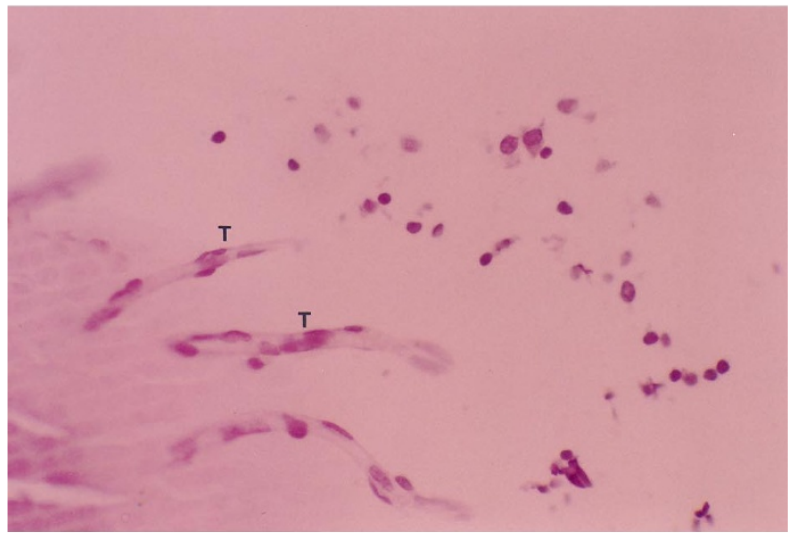

c

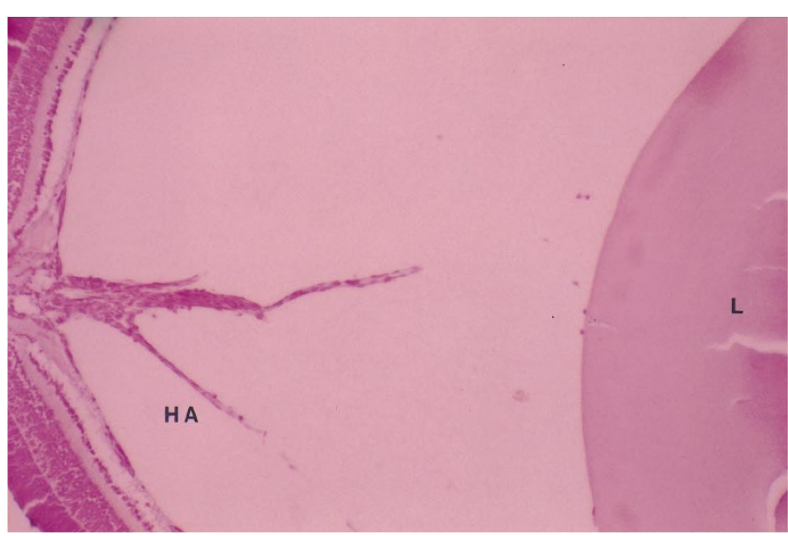

Figure 3 (a, b) Eye from 7 day old BALB/c mouse $(7 \mu \mathrm{m}$ section counterstained with hematoxylin) showing lens $(\mathrm{L})$, primary vitreous, including tunica vasculosa lentis (T), and abundant macrophages (hyalocytes) (a) $10 \times$

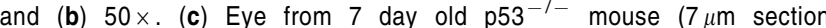
counterstained with hematoxylin) showing lens $(L)$ and primary vitreous, including hyaloid artery $(\mathrm{HA})$, but few macrophages $(10 \times)$ hyaloid vasculature at a given time point we detected very few TUNEL positive cells, and in most cases only one or two labelled cells. Looking at a large number of sections and plotting the percentage of positive sections per time

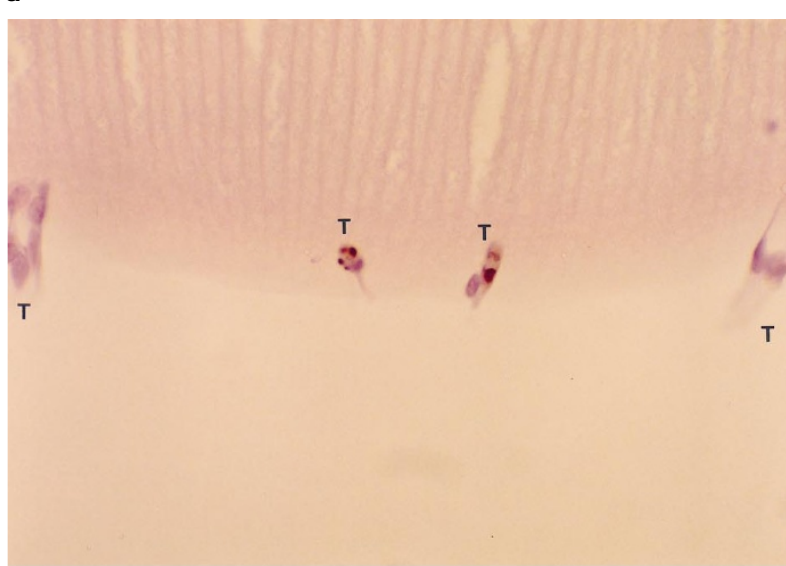

b

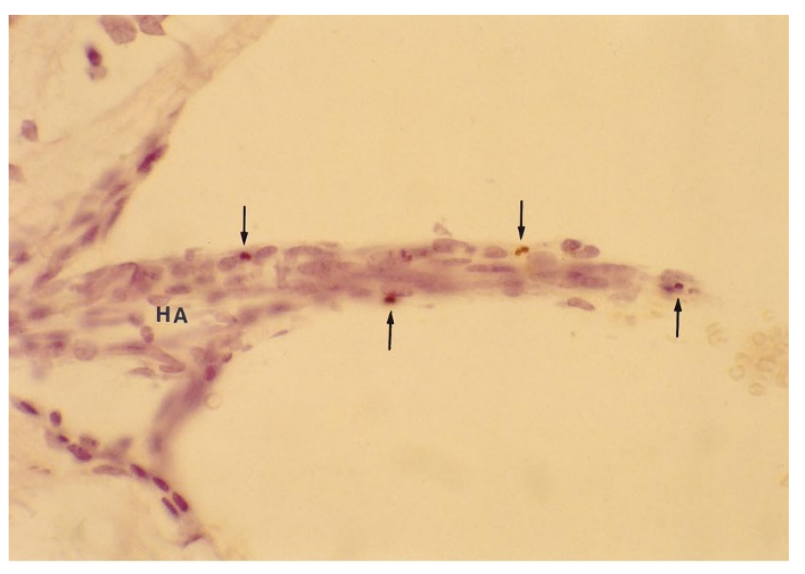

C

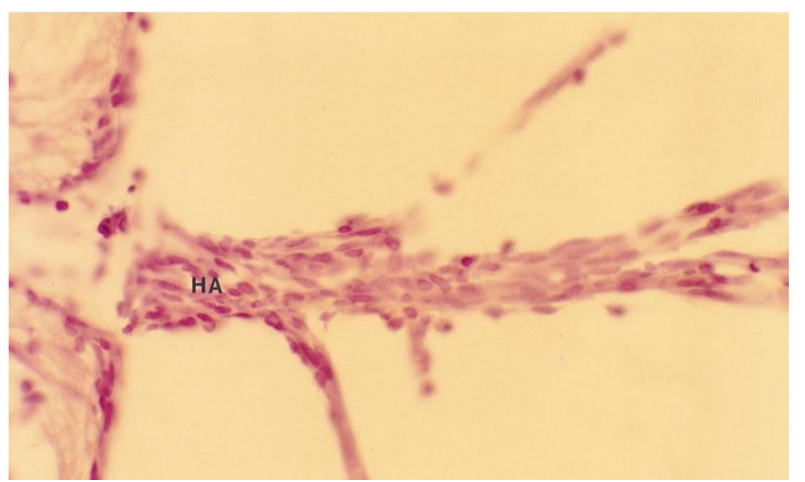

Figure $4(\mathbf{a}, \mathbf{b})$ TUNEL labelled cells in a 7 day old BALB/c mouse eye $(7 \mu \mathrm{m}$ section counterstained with hematoxylin) showing (a) the regressing tunica vasculosa lentis $(T)$ - whilst the nuclei in the longitudinal sections through the vessels on either side of the figure appear normal, the TUNEL positive nuclei in the centre appear fragmented (arrows) and the vessels atrophic $(50 \times)(\mathbf{b})$ the regressing hyaloid artery $(\mathrm{HA})$ - some of the TUNEL positive nuclei appear condensed or fragmented (arrows) $(50 \times)$. (c) Hyaloid artery (HA) in 7 day old p53 $3^{-1-}$ mouse eye showing no positive cells following TUNEL staining $(7 \mu \mathrm{m}$ section counterstained with hematoxylin, $50 \times$ ) 


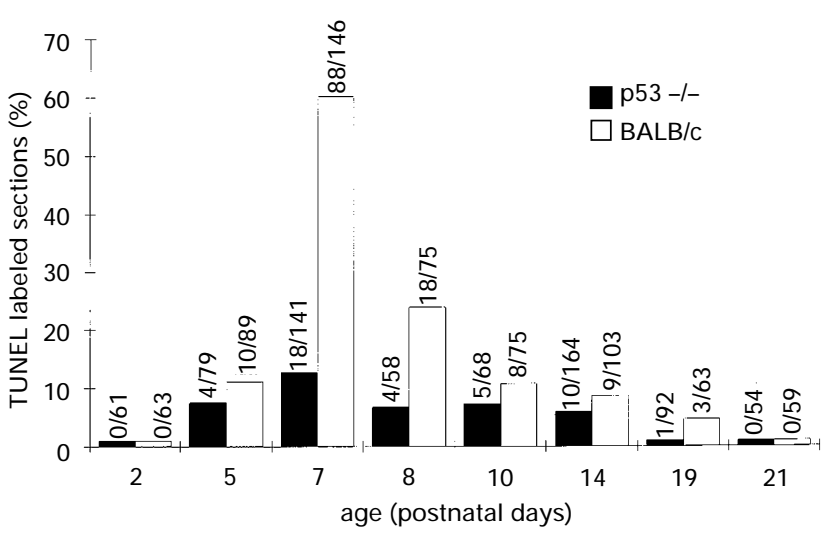

Figure 5 Graph showing the percentage of TUNEL labelled sections through the hyaloid artery and the tunica vasculosa lentis in $\mathrm{p} 53^{-/-}$and BALB/c mice at various time points between 2 and 21 days after birth. The exact numbers are also given

point, the picture becomes clearer: TUNEL labelled cells were observed between 5 and 19 days after birth with a sharp peak around day 7 indicating a peak of apoptosis during normal regression of the hyaloid vascular. There were no TUNEL positive cells at day 2 or at day 21 . By comparison, the percentage of TUNEL positive sections in p53 ${ }^{-1-}$ eyes, over the whole time course, is threefold lower (8.5\% of sections taken from $\mathrm{p} 53^{-1-}$ mice compared to $24.5 \%$ of sections from BALB/c mice) and lacks the prominent peak at day seven (Figure $4 \mathrm{c}$ and 5).

\section{Discussion}

Several light and electron microscopic studies have catalogued the early morphology and/or regression of the primary vitreous in the human eye (Sellheyer and Spitznas, 1987), as well as in other animals including the rat (Hollenberg and Dickson, 1971; Cairns, 1959; Latker, 1981), the rabbit (Jack, 1972; Gloor, 1973b) and the dog (Boeve et al, 1988). Gloor was the first to describe the development of the mouse vitreous (Gloor, 1973a). The histological analysis of our material corresponds with his previous description. Ultrastructural studies on the regressing primary vitreous have not elucidated the mechanisms involved, and whilst this type of tissue regression and remodelling has been studied intensively at the histological level, little is known about the cellular and molecular mechanisms which might lead to involution of the primary vitreous.

There is no consensus as to the absolute defining characteristics of apoptosis. Although it is possible that TUNEL positively could arise from DNA breaks induced by other processes, in the current context of the developmental regression of a tissue, and in the presence of apoptotic body formation, it seems most probable that TUNEL labelling is identifying apoptotic cells. We therefore conclude that regression of primary vitreous normally occurs by apoptosis. We found very few TUNEL labelled cells per section at each time point. This is consistent with the relatively small number of cells within the structure of interest present on a single $7 \mu \mathrm{m}$ section and the fact that the apoptotic process is very rapid and may be completed within a few hours. The peak of TUNEL positivity at 7 days reflects not only the percentage of cells entering the cell death pathway but also the number of cells present and the rate of clearance of labelled cells.

We have observed that apoptosis in the primary vitreous in $\mathrm{p} 53^{-1-}$ mice occurs at a much lower frequency compared with wild-type controls and that these animals develop a phenotype similar to PHPV. Our data provide strong evidence that at least one cause of PHPV is absence of the p53 gene product. Failure of the apoptotic process in the hyaloid vasculature in the $\mathrm{p} 53^{-1-}$ mice not only leads to incomplete regression of the hyaloid vasculature but also to abnormal proliferation of the tunica vasculosa lentis. PHPV has also been described in some dog breeds: originally in the Doberman pinscher and later in the Staffordshire bull terrier (Stades, 1980; Curtis et al, 1984). In the former breed, initial over-development as well as subsequent incomplete regression of primary vitreous is seen (Boeve et al, 1988). Retinal glial elements such as Mueller cells and fibrous astrocytes as well as vitreous cells contribute to the formation of PHTVL (Boeve et al, 1990; 1993). We did not observe any over-development of the primary vitreous in the p53 ${ }^{-1-}$ mice: at the earliest time points the amount of vasculature is very similar to that of the wild-type control.

We have observed macrophages, known in the vitreous as hyalocytes, on many BALB/c eye sections, but in much higher numbers from day 7 after birth onwards. Since the hyaloid vasculature is not surrounded by a cellular environment but lies in a primarily acellular vitreous, it is conceivable that these macrophages migrate into the vitreous in order to phagocytose the cellular debris resulting from tissue regression. In other instances of tissue remodelling in which there is apoptosis, surrounding cells are presumed to phagocytose cellular debris. The fact that we observed most macrophages after the period of peak apoptosis in BALB/c animals and very few in $p 53^{-1-}$ mice, would support this explanation.

The presence of macrophages in the involuting primary vitreous has been known for some time. Macrophages have been found to occlude the capillary lumen of the vasa hyaloidea propria in the rabbit eye (Jack, 1972) and have also been found in the tunica vasculosa lentis in human eyes at early gestation (Sellheyer and Spitznas, 1987). However, the clearest indication that macrophages play a role in the regression of primary vitreous has been provided by the analysis of transgenic mice in which a specific subset of mature macrophages, including hyalocytes, had been ablated (Lang and Bishop, 1993). Remnants of the hyaloid vasculature were found in the vitreous of transgenic animals at a time at which control animals showed complete regression. The authors concluded that macrophages are actively involved in the tissue remodelling of the primary vitreous and the pupillary membrane. Unfortunately their observation time was limited to the 23 day life-span of these animals, which exhibited a very complex phenotype, including other eye abnormalities. However, within this period there was a slow regression of the hyaloid vasculature. It is therefore possible that the absence of hyalocytes merely increased the time taken for removal of 
debris. Alternatively, macrophages may be critically involved in regression of the hyaloid vasculature, but it is clear from our study that the process of remodelling is at least multi-factorial and is heavily reliant upon p53dependent apoptosis.

Whilst p53 is clearly involved in the induction of G1phase cell-cycle arrest or programmed cell death in response to DNA damage, recent experiments provide other evidence of a role for p53 in development. In about $20 \%$ of $\mathrm{p53}^{-1-}$ mouse embryos, the normal process of neural tube closure fails and the animals display exencephaly and craniofacial malformations (Sah et al, 1995; Armstrong et al, 1995). Sah et al examined the pattern of apoptosis along the neural tube using the TUNEL method and found no difference between viable $\mathrm{p} 53^{-1-}$ and wild-type embryos (Sah et al, 1995). However, the authors could not exclude the possibility that an apoptotic defect was only occurring in the exencephalic embryos,

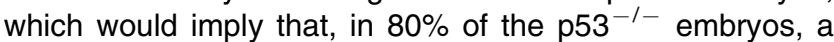
compensatory mechanism of apoptosis was leading to normal development. Whilst these developmental disorders were predominantly found in non-viable embryos, the development of PHPV reported here is the first evidence for a highly penetrant role for p53 in postnatal development. Patients Li-Fraumeni syndrome, a rare disease characterised by the occurrence of diverse mesenchymal and epithelial neoplasms at multiple sites, carry a germ line mutation in one p53 allele (Srivastava et al, 1990). With regard to the phenotype in the $\mathrm{p} 53^{-1-}$ mice described here, it is perhaps not surprising that PHPV has not been described in these patients since PHPV is also absent in p53 ${ }^{-/+}$mice.

The first indication that p53 might be involved in the regression of the hyaloid vasculature was provided by Pan and Griep, 1995, who briefly noted that neonatal p53deficient mice have a more extensive vascular plexus than wild-type controls. Our results not only confirm the observation by Pan and Griep in neonatal p53-deficient mice, but provide evidence that p53-dependent apoptosis is normally required for regression of the hyaloid vasculature, which we have shown, in the absence of p53, persists well into adulthood. Furthermore we have demonstrated that the phenotype in p53-deficient animals resembles PHPV in humans. In both cases, persistence of the hyaloid vasculature results in cataracts.

Our results demonstrate that apoptosis is the underlying mechanism in the regression of the primary vitreous in the developing mouse eye. The presence of PHPV in p53deficient mice strongly supports the link between p53 deficiency and developmental abnormalities and reflects the important role of p53 in mediating apoptosis in normal vitreal development.

\section{Materials and Methods}

\section{Animals}

Mice homozygous for a targeted disruption of the p53 gene on a $129 \mathrm{SvHsd}$ background and which do not produce any functional p53 have been previously described (Clarke et al, 1993). The mutation was introduced into a BALB/cOlaHsd background by crossing for four generations and a homozygous line was subsequently produced $\left(\mathrm{p} 53^{-1-}\right)$ which was also used to generate animals which were heterozygous at this locus ( $\mathrm{p} 53^{-/+}$. Thirty four age matched BALB/c

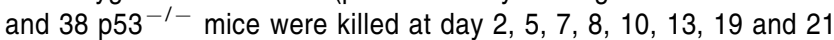
days after birth. Between 8 and 16 eyes were collected at each time point for each strain of mice and then fixed and embedded for light microscopy. After ophthalmoscopic examination of a large number of adult (over 3 week) BALB/c and $p 53^{-1-}$ mice, some eyes were prepared for semi-thin sectioning and some lenses were prepared for SEM. All procedures conformed to the ARVO Statement for the Use of Animals in Ophthalmic and Vision Research.

\section{Light microscopy}

Eyes were fixed in $4 \%$ paraformaldehyde and paraffin-embedded. Horizontal sections were cut $7 \mu \mathrm{m}$ thick through the lens in such a way that large parts of the tunica vasculosa lentis could be demonstrated at its superior pole and that at deeper levels a maximum of the hyaloid artery and the vasa hyaloidea propria would be present on the section. An average of 10 sections per eye through the tunica vasculosa lentis and hyaloid artery were obtained with this technique. One or two sections were stained with $\mathrm{H} \& \mathrm{E}$ in order to confirm that the specimen had been sectioned at the appropriate place and to assess pathology. In order to detect DNA double strand breaks as they occur in apoptotic cells we applied a modified TUNEL technique (Gavrieli et al, 1992). Instead of dUTP, this in situ $3^{\prime}$ tailing reaction uses biotinylated dATP with terminal deoxynucleotidyl transferase (TdT) to label the 3 hydroxyl termini of DNA fragments in apoptotic cells. Visualisation was carried out using an ABC-peroxidase kit (DAKO, City). These sections were counterstained with hematoxylin. They were then analyzed by light microscopy. Every section with TUNEL positive cells within the hyaloid vasculature was marked and counted for statistical analysis.

\section{Semi-thin sections}

Eyes were immersion fixed in a mixture of $3 \%$ glutaraldehyde and $1 \%$ paraformaldehyde buffered to $\mathrm{pH} 7.4$ in $0.1 \mathrm{M}$ sodium cacodylate- $\mathrm{HCl}$ for a minimum period of $2 \mathrm{~h}$ at room temperature. After removal of a corneal calotte, eyes were rinsed 3 times in $0.1 \mathrm{M}$ sodium phosphate buffer $(\mathrm{pH} 7.4)$ and immersed in a $1 \%$ aqeous solution of osmium teroxide for 2 hat $4{ }^{\circ} \mathrm{C}$. Next the specimens were dehydrated with a single immersion in $50 \%, 70 \%$ and $90 \%$ and three changes of $100 \%$ ethanol followed by two changes of propylene oxide. Resin infiltration was carried out overnight with a $1: 1$ mixture of propylene oxide : araldite, followed by two 3 h changes of neat resin prior to embedment and overnight curing at $60^{\circ} \mathrm{C}$. Semi-thin $(1 \mu \mathrm{m})$ thick sections passing through the optic nerve head were cut using a Leica Ultracut $S$ microtome. They were stained with a $1 \%$ mixture of toluidine blue and Azure II in $50 \%$ ethanol, dried on a hotplate and mounted in DPX.

\section{Scanning electron microscopy}

Eye cups and lenses destined for S.E.M. examination were fixed in $3 \%$ glutaraldehyde and $1 \%$ paraformaldehyde in $0.1 \mathrm{M}$ sodium cacodylate- $\mathrm{HCl}$ buffer at $\mathrm{pH}$ 7.4. Following a rinse of $0.1 \mathrm{M}$ cacodylate- $\mathrm{HCl}$ buffer, specimens were postfixed for $2 \mathrm{~h}$ with $1 \%(\mathrm{w} / \mathrm{v})$ aqueous solution of osmium tetroxide, dehydrated through sequential $15 \mathrm{~min}$ immersions in 50, 70, 90 and $3 \times 100 \%$ ethanol and critical-point dried. Dried specimens were mounted and sputter coated with gold using an Emitech K550 unit prior to examination in a JEOL 6100 S.E.M. interfaced with JEOL WINSEM optical disc archiving system. 


\section{In vivo assessment}

A large number of adult (age 3 weeks or older) BALB/cOlaHsd $(n=60)$, p53 $3^{-1-}(n=60),{\mathrm{p} 53^{-1+}}^{-1}(n=60)$ and 129SvHsd mice $(n=30)$ were assessed by ophthalmoscopy in order to diagnose PHPV or the related secondary lens changes. Mice were anaesthetised by ip injection of $0.2 \mathrm{ml}$ Hypnorm (Janssen Pharmacuetical Ltd, Oxford), and Hypnovel (Roche, Welwyn Garden City) mixed 1:1:6 with distilled water. Following pupillary dilation with $1 \%$ Tropicamide (1\% Mydriacyl, Alcon Labs (UK) Ltd., Hemel Hempstead), the eyes were gently protruded using a rubber sleeve and subsequently covered with $2 \%$ hydroxypropylmethylcellulose in phosphate buffered saline and a cover slip. This allowed good visualisation of lens, vitreous and retina through a Zeiss operating microscope with a camera attachment for documentation (Ali et al, 1996).

\section{Acknowledgements}

We thank Dr PMG Munro (Electron Microscopy Unit, Institute of Ophthalmology, UCL) for his assistance with this project. This work was supported by the Medical Research Council. MBR was supported by Deutsche Forschungsgemeinschaft $\operatorname{Re} 1121 / 1-1$ and Deutsche Retinitis Pigmentosa Vereinigung.

\section{References}

Ali RR, Reichel MB, Thrasher AJ, Levinsky RJ, Kinnon C, Kanuga N, Hunt DM and Bhattacharya SS (1996) Gene transfer into the mouse retina mediated by an adeno-associated viral vector. Human Molecular Genetics 5: 591-594

Armstrong JF, Kaufman MH, Harrison DJ and Clarke AR (1995) High-frequency developmental abnormalities in p53-deficient mice. Current Biol. 5: 931-936

Balazs EA, Toth TZ and Ozanics V (1980) Cytological studies on the developing vitreous as related to the hyaloid vessel system. Graefe's Arch. Clin. Exp. Opthalmol. 217: 71-85

Boeve MH, Van der Linde-Sipman T and Stades FC (1988) Early morphogenesis of persistent hyperplastic tunica vasculosa lentis and primary vitreous. Invest. Opthalmol. Vis. Sci. 29: 1076-1086

Boeve MH, Van der Linde-Sipman T, Stades FC and Vrensen GFJM (1990) Early morphogenesis of persistent hyperplastic tunica vasculosa lentis and primary vitreous. Invest. Ophthalmol. Vis. Sci. 31: 1886-1894

Boeve MH, Vrensen GFJM, Willekens BLJC, Stades FC and Van der Linde-Sipman T (1993) Early morphogenesis of persistent hyperplastic tunica vasculosa lentis and primary vitreous (PHTVL/PHPV). Graefe's Arch. Clin. Exp. Ophthalmol. 231: $29-33$

Cairns JE (1959) Normal development of the hyaloid and retinal vessels in the rat. Brit. J. Ophthalmol. 43: 385-393

Clarke AR, Purdie CA, Harrison DJ, Morris RG, Bird CC, Hooper ML and Wyllie AH (1993) Thymocyte apoptosis induced by p53-dependent and independent pathways. Nature 362: $849-852$

Curtis R, BarnettKC and Leon A (1984) Persistenthyperplastic primary vitreous in the Staffordshire bull terrier. Vet Rec. 115: 385

Donehower AL, Harvey M, Slagle BL, McArthur MJ, Montgomery Jr CA, Butel JS and Bradley A (1992) Mice deficient for p53 are developmentally normal but susceptible to spontaneous tumours. Nature 356 : 215-221
Gavrieli Y, Sherman Y and Ben-Sasson SA (1992) Identification of programmed cell death in situ via specific labeling of nuclear DNA fragmentation. J. Cell Biol. 119: $493-501$

Gloor BP (1973a) Zur Entwicklung des Glaskörpers und der Zonula Graefe's Arch. Clin. Exp. Ophthalmol. 186: 299-309

Gloor BP (1973b) Zur Entwicklung des Glaskörpers under der Zonula Graefe's Arch. Clin. Exp. Ophthalmol. 186: 311-328

Hollenberg MJ and Dickson DH (1971) Scanning electron microscopy of the tunica vasculosa lentis of the rat. Canad. J. Ophthalmol. 6: 301-310

Jack RL (1972) Ultrastructure of the hyaloid vascular system. Arch. Ophthal. 87: $555-567$

Jacks T, Remington L, Williams BO, Schmitt EM, Halachimi S, Bronson RT and Weinberg RA (1994) Tumor spectrum analysis in p53-mutant mice. Curr. Biol. 4: $1-7$

Jokl A (1927) Vergleichende Untersuchungen über den Bau und die Entwicklung des Glaskörpers und seinem Inhaltsgebilde bei Wirbeltieren und Menschen. Thesis, Upsala-Stockholm, Almquist Wiksells Boktryckei A.B.

Lang RA and Bishop JM (1993) Macrophages are required for cell death and tissue remodelling in the developing mouse eye. Cell 74: 453-462

Latker $\mathrm{CH}$ (1981) Regression of the tunica vasculosa lentis in the postnatal rat. Invest. Ophthalmol. Vis. Sci. 21: 689-699

Mann IC (1964) The development of the human eye. (New York: Grune and Stratton Inc.).

Morgenbesser SD, Williams BO, Jacks T and DePinho RA (1994) p53-dependent apoptosis produced by Rb-deficiency in the developing mouse lens. Nature 371 : $72-74$

Norimura T, Nomoto S, Katsuki M, Gondo Y and Kondo S (1996) p53-dependent apoptosis suppresses radiation-induced teratogenesis. Nature Medicine 2: $577-580$

Pan H and Griep AE (1995) Temporally distinct patterns of p53-dependent and independentapoptosis during mouse lens development. Genes \& Dev. 9:21572169

Papermaster DS (1997) Apoptosis of the mammalian retina and lens. Cell Death Differ. 4: $21-28$

Purdie CA, Harrison DJ, Peter A, Dobbie L, White S, Howie SEM, Salter MD, Bird CC Wyllie AH, Hooper ML and Clarke AR (1994) Tumor incidence, spectrum and ploidy in mice with large deletion in the p53 gene. Oncogene 9: 603-608

Reese AB (1955) Persistent hyperplastic primary vitreous. Am. J. Ophthalmol. 40: $317-331$

Sah VP, Attardi LD, Mulligan GJ, Williams BO, Bronson RT and Jacks T (1995) A subset of p53-deficient embryos exhibit exencephaly. Nature Genetics 10: 175187

Sellheyer K and Spitznas M (1987) Ultrastructure of the human posterior tunica vasculosa lentis during early gestation. Graefe's Arch. Clin. Exp. Ophthalmol. 225: $377-383$

Srivastava S, Zou Z, Pirollo K, Blattner W and Chang EH (1990) Germ-line transmission of a mutated p53 gene in a cancer-prone family with Li-Fraumeni syndrome. Nature 348: $747-749$

Stades FC (1980) Persistent hyperplastic tunica vasculosa lentis and persistent hyperplastic primary vitreous in 90 closely related Doberman pinschers: Clinical aspects. J. Am. Anim. Hosp. Assoc. 16: 739

Virchow R (1853) Über den menschlichen Glaskörper Virchows. Arch. Pathol. Anat. 5: 278

White $E$ (1996) Life, death, and the pursuit of apoptosis. Genes and Dev. 10: 1-15 